\title{
Reaffirming Individual Responsibility in Distributive Justice: A Case Study of the Chinese Healthcare System
}

\author{
Ziyu Liu ${ }^{1} \&$ Martin Buijsen ${ }^{2}$ \\ ${ }^{1}$ Law \& Health Care (R \& G), Institute of Health Policy \& Management (iBMG), Erasmus University Rotterdam, \\ Rotterdam, The Netherlands \\ ${ }^{2}$ Professor of Health Law, Institute of Health Policy \& Management (iBMG) c/o Erasmus School of Law, Erasmus \\ University Rotterdam, Rotterdam, The Netherlands
}

Correspondence: Ziyu Liu, Law \& Health Care (R \& G), Institute of Health Policy \& Management (iBMG), Erasmus University Rotterdam, P. O. Box 1738, 3000 DR, Rotterdam, The Netherlands.

Received: February 3, 2017

doi:10.11114/ijsss.v5i4.2186

\author{
Accepted: February 22, $2017 \quad$ Available online: March 8, 2017
}

URL: https://doi.org/10.11114/ijsss.v5i4.2186

\begin{abstract}
The human rights-based approach is widely employed in achieving distributive justice in health care. In the light of a common understanding of the approach, protecting the right to health as a human right relies heavily on addressing state accountability. However, the corresponding measures are put forward unevenly on the national level and generally achieve less than expected. Deficiencies, such as inefficient utilization and the free-rider problem, are increasingly obvious along with the aging population. In the context of the Chinese healthcare system, the paper suggests that drawing attention to the importance of individual responsibility is beneficial to improve the performance of the human rights-based approach in reforming healthcare systems towards more justice. Furthermore, raising the issue of individual responsibility can help to achieve equilibrium between the protection of individual rights and the sustainability of the healthcare system.
\end{abstract}

Keywords: Chinese healthcare system reform, state accountability, individual responsibility, human rights-based approach, healthcare justice

\section{Introduction}

Over the years, both national and international communities have made great efforts to protect and promote the right to health towards "Availability, Accessibility, Acceptability, and Quality" (AAAQ). Typically, the corresponding approach is the human rights-based approach (HRBAP). In the light of a general understanding, implementing the HRBAP to health is mainly through emphasizing state accountability in consideration of the fact that the human rights discourse is always literally understood as a protection against the state. This understanding seems to be more convincing after General Comment No. 14 becomes effective. Furthermore, addressing the state accountability accounts for the majority of researches on the HRBAP and health (including Chapman, 1994, 2010, 2015; Toebes, 1999a, 1999b, 2006, 2015; Daniel \& Sabin, 1998, 2002, 2008; Daniel, 2001, 2008, 2011; Fisher, Shang, \& Blaxland, 2010; Schrecker, Chapman, Labonté, \& De Vogli, 2010). However, under the influence of inefficient utilization and the free-rider problem, implementing the HRBAP through emphasizing state accountability corresponds poorly with reality, especially in countries where lack of effective supervisory systems exists. Moreover, it gives rise to a tendency of indulging the preferences of irresponsible individuals at the expense of people in real need. Considering the diversity of healthcare systems worldwide, it makes sense to start from a specific case and thereafter discuss the possibility of generalization. Thus, this paper addresses the issue in the context of the Chinese healthcare system in which deficiencies are exposed more obvious along with the aging population. It suggests drawing attention to the importance of individual responsibility, i.e. the promotion of self-management skills in health, in reforming healthcare systems towards justice. The paper concludes that raising the issue of individual responsibility not only strengthens the practical value of the HRBAP in shaping certain healthcare systems, but also helps to achieve equilibrium between the protection of individual rights and the sustainability of the healthcare system.

This paper consists of four sections, including the introduction as section one and the conclusion as section four. Section two, from a practical perspective, begins by setting out the basic structure and the progressive reforms of the 
Chinese healthcare system. Thereafter, it demonstrates that insufficient availability of medical services and unaffordable health care are perennial issues which might be even worse under an ageing China. Since these problems are shared worldwide, section three delineates the HRBAP which is a widely adopted approach in achieving distributive justice in health care from a theoretical perspective. This section is sub-divided into two parts. The first sub-section explores state accountability as a common strategy in implementing the HRBAP to health. Considering the drawbacks of this strategy, the paper proposes an idea of promoting individual responsibility as an alternative viewpoint to strengthen the practical performances of the HRBAP. The second sub-section articulates a few points on how to adopt the individual responsibility to improve the performance of the HRBAP in reforming healthcare systems towards justice. Finally, the paper concludes with several suggestions to forward the current Chinese healthcare system reform.

\section{A Case Study of the Chinese Healthcare System}

\subsection{The Basic Structure}

From a macro perspective, the Chinese healthcare system has a multi-level structure, including a public health service system, a medical care system, and a medical security system. Generally, it is a hybrid of public and private elements, allocating healthcare resources via state-intervention and market-transaction (Ho, 2014).

To be specific, the public health service system with a nationwide function accounts for "disease prevention and control, health education, maternity and child care, mental health, health emergency response, blood collection and supply, health supervision, and family planning as well" (Note 1). Unlike the public health service system, the medical care system is constructed differently in rural and urban China. In rural areas, it is mainly delivered by three institutions: county hospitals, township hospitals, and village clinics. In urban China, however, it is delivered by general hospitals and specialized hospitals. Besides the above regular medical institutions, several community clinics emerge to take care of the preliminary diagnosis and treatment of certain ordinary illnesses like flu and fever. With regard to the medical security system, it is designed as a multi-level insurance schemes which comprise three basic health insurance schemes: the basic medical insurance for working urban residents, the basic medical insurance for non-working urban residents, and the new type of cooperative medical care for rural residents. In 2012, nearly 95 percent of the Chinese people were under the protection of these three basic health insurance schemes. Despite the high rate of coverage, the Chinese healthcare system still faces several crucial problems and challenges, especially the insufficient availability of medical services and unaffordable health care.

From a micro perspective, the Chinese healthcare system is special in terms of its financial support, administrative structure, as well as legal regulations. These special aspects in turn will aggravate the existing formidable problems over time.

Firstly, the financial budget is mainly guaranteed by local governments rather than by the central government. Consequently, health policies launched by the central government are carried out unevenly from province to province, which contributes to the geographical disparities of health care while impedes equal accessibility. Even worse, it poses a threat to social stability. Secondly, the Chinese healthcare system is administrated uniquely. Nearly all of the general hospitals in China are "Gonggong Shiye Danwei", which refers to organizations that are established by the government with state-owned facilities. Furthermore, the employees of these organizations enjoy the same welfare conditions as civil servants (Ho, 2014). Thirdly, the legislative and judicial supports for the Chinese healthcare system are far from adequate. Overall, the Chinese healthcare system performs poorly concerning judicial remedy, owing to the fact that it relies on a "decentralized legislation model" (Note 2) and a dependent judicial system. According to an authoritative statistic, most health-related cases are solved without resorting to judicial sources, such as "Shangfang". Compared to judicial remedy, "Shangfang" is believed to be more accessible and friendly. It depends on an administrative system called "Xinfang" (letters and visits) which allows citizens to solve their conflicts by means of writing a letter of complaint or visiting directly to certain departments of the government for redress (Ho, 2014, p. 273). Yet, patients are actually reluctant to seek help in this way as well due to the fact that the government plays not only as an executant but also as a supervisor of the Chinese healthcare system. Therefore, conflicts have no legitimate way to resolve and eventually result in violence against physicians. From another point of view, these tough issues are incentives triggering the progressive reforms of the Chinese healthcare system.

\subsection{The Progressive Reforms}

The principle of solidarity has been admired by Chinese society throughout a long history. Under this principle, it is natural that the Chinese government plays a leading role in nearly all kinds of social services (Yip \& Hsiao, 2015). During that time, almost every aspect of social life is controlled by state-owned enterprises which are established, managed, and monitored entirely by the government. In health care, the financial budget was adequate because a priority was given to a nation-wide coverage rather than the quality of service. The annual reports show a great decrease in mortality and a steady increase in life expectancy (Note 3). Apparently, the original healthcare system functioned 
well without any noticeable problems concerning availability and affordability (financial accessibility). However, improvements are accompanied by some hidden problems. The first problem relates to the "barefoot doctor". It represents a certain group of people who haven't received adequate education but in charge of the health care in rural China. Along with "Hezuo Yiliao" (Corporative Healthcare Scheme) and "Sanceng Baozhang" (Three-tier Preventive Healthcare Net), the mechanism of health care in rural China was recommended by WHO as a model at that time. As time goes on, the legitimacy of the barefoot doctors' medical practices becomes questionable which in turn threatens the whole healthcare system of rural China. The second problem relates to the "financial budget". The national coverage of health care was achieved on a rather low level. Every small increase of healthcare quality demands additional financial support. These increasing demands might put the realization of other social goods on hold. The third problem relates to the "inefficient utilization". The inefficient utilization is not a special issue that merely happens in health care, but the entire Chinese society suffers from it in different ways. The lack of competition threw the government-run centrally planned strategy into a tight corner, which unexpectedly simulates free market thinking.

The first round of healthcare system reform was initiated in 1978. At that time, the Chinese government liberalized its economic system from a central-planning economy into socialistic market economy with a premise that the free market should be more productive in virtue of efficient distributive mechanisms. It is certainly an innovative strategy, trying to find a third way to balance the government's central planning and the free market mechanism in the context of China. Furthermore, the Chinese government became increasingly active in the international arena at that time, signing a series of international documents (Note 4) and taking great efforts to cooperate with the international community. With such a background, the first round of healthcare system reform was launched. Consistent efforts were devoted to various aspects, including slowing down the increasing financial budget and modifying the salary-structure of physicians. During that time, public hospitals were changed from "public good-oriented" institutions into "for-profit" entities. Undeniably, achievements were made. For instance, life expectancy grew to seventy-one point eight years in 2001, higher than the average of the whole world (sixty-five years) (Wang, 2004, p. 7). Nevertheless, deficiencies are obvious. First of all, efficiency might be improved at the expense of fairness in distributing health care. Although the market mechanism in China has due consideration to fairness, it still gives priority to efficiency (Note 5). Emphasizing market mechanism intensifies the tendency of treating health care as an exchangeable commodity, which indicates that the ability to pay is decisive of the allocation of health care. However, health care is different. Humane caring cannot be ignored in distributing health care. Therefore, a mechanism of price-control was put forward by the central government with the aim of protecting vulnerable groups from the potential side effects of the market mechanism. However, the price controlling mechanism unexpectedly contributes to the "Yiyao Buyi" ('drug mark-ups'). The 'drug mark-ups' (WHO et al., 2016, p. 2) is a policy permitting public hospitals to make extra profits through prescriptions. It strengthens the interest relations between physicians, hospitals, and pharmaceutical companies. The profit-making behaviors deviate from the original objectives of the public hospitals and instead drive the hospitals to make as much money as possible. These medical expenses, which are excluded from reimbursements, become the burdens that are ultimately placed on the patients (Note 6). If a family member unfortunately suffers from an incurable disease, such as cancer, it would be equal to bankrupting his or her family due to the catastrophically expensive health care. Even worse, the market mechanism might open the door to corruption in health care, such as the so-called "Hongbao" (red envelope), if without restrictions and regulations. Furthermore, it would create another extra burden to the patients. The unaffordable health care makes people, especially the worse off, hesitant to get health care. Moreover, it causes healthcare disparities more pronounced, not only geographically but also in terms of wealth and poverty. Moreover, the widening disparities might result in an unstable and unsustainable society where no individual is able to develop his or her well-being. These problems were aggravated after the epidemic of SARS in 2003. Some scholars argued that it was the market-oriented reform that deteriorated the situation (Liu, 2004; Wang, 2004; Li, Chen, \& Powers, 2012). Seemingly, this round of reform led the Chinese healthcare system to the other extreme with too much emphasis on market forces, which inevitably resulted in an indifferent society.

Dealing with these parameters, the Chinese government planned to reshape the whole healthcare system with an aim of "providing safe, efficient and affordable basic health care for all Chinese residents by 2020." It was a starting point of the second round of reform, launched in 2009. Besides the regular budget, an extra amount of eight hundred fifty billion Chinese Yuan has been committed to support the coming round of reform (Meng \& Tang, 2010). Going over all the efforts, the second round of reform moved backward to emphasize state accountability in distributing health care. Influenced by the "Primary Health Care" (WHO, 2008), the fundamental aim of a healthcare system is to guarantee a decent minimum of care. Accordingly, the Chinese government reconfirmed its obligation and switched its financial budget to achieve that target. On the basis of official reports, the total amount of healthcare expenses in China is on the rise, occupying 5.57 percent of GDP in the year of 2013. Among these healthcare expenses, the expenditure of the Chinese government accounts for 30.1 percent, which is 2.6 per cent higher than the year of 2009 (Fang, 2015, p. 38). As guaranteed by the government, nearly all of the Chinese people are able to get access to the basic health care. 
Nevertheless, the quality of health care still needs to be improved according to the $A A A Q$. One possible reason is that "a decent minimum" has a deficit that it might limit the scope and the content of the state-supported health care. The majority of costly diseases are actually excluded from the list of diseases which can be reimbursed. Therefore, people are still suffering from catastrophically expensive medical services. In addition, there are two contradictions. One is that the majority of medical demands are converged to the large hospitals with supposed well equipped medical facilities while very few medical functions are delivered by the hospitals and clinics in the countryside. The other one is that the number of physicians is decreasing while the number of patients is increasing. As mentioned before, the "barefoot doctors" are the main force to support the health care in rural China. However, their legal status turns out to be illegal over time, which indicates that rural China might be short of physicians and nurses. Meanwhile, urban China also confronts the same problem but for different reasons. It is partially because of the declining number of medical graduates. Because of the high risks, people are reluctant to choose medical profession as a lifelong career option.

In response, the Chinese government planned to take extra steps to deepen the healthcare system reform in 2014. Among these newly issued measures, major steps consist of formulating "Fenji Zhenliao" (a system of Tiered Diagnosis and Treatment), reorganizing the institutional structure of public hospitals, and forbidding the 'drug mark-ups'. However, none of them is easy to carry out. Taking the 'drug mark-ups' as a simple example, it is tough to eliminate the profound effects of the 'drug mark-ups', not only because of the existing solid interest relations but also due to the fact that it accounts for one part of physician's income. Unfortunately, there is no alternative way except increasing financial investments to make up the part that the 'drug mark-ups' used to account for. Therefore, problems like inefficiencies, free riding, heavy financial challenges, and unsustainable development still set back the improvement of the Chinese healthcare system. Apart from these perennial problems, the Chinese healthcare system faces new challenges, such as the second-child policy brought by the aging population and the widespread of e-health triggered by the advancement of high technology. These new challenges might make the existing healthcare problems even worse. More important, it questions state accountability: Should these ongoing efforts continue protecting the right to health as a human right by emphasizing state accountability? Are there alternatives which could be employed to achieve the same results as, or even more than, addressing state accountability? Thus, it is vital to think the responsibility of other stakeholders in the Chinese healthcare system, in particular the individual responsibility.

\section{Reaffirming Individual Responsibility in Healthcare Distribution from a Theoretical Perspective}

The essential meaning of responsibility has three interpretations according to Oxford Dictionaries. The first refers to "a duty" or "a state of control"; the second signifies the fact of being "accountable" or "to blame for something"; the third relates to "autonomy in decision making". In a healthcare system, responsibility is diverse because of different stakeholders: the state, the non-governmental organizations (NGOs), individuals, hospitals, and pharmaceutical companies. However, it is impossible to cover all stakeholders involved while analyzing their roles in detail, this paper only sketches out the state and the individual since these two are crucial participants and their relationship has a significant effect on designing healthcare systems (Roberts, Hsiao, Berman, \& Reich, 2008, p. 50).

\subsection{The Human Rights-based Approach (HRBAP) and the State Accountability}

The right to "the enjoyment of the highest attainable standard of health" was first legally recognized by the Constitution of the WHO (1946), and thereafter stipulated in numerous international human rights treaties. The outbreak of certain serious diseases, such as HIV and AIDS, intensified the trend of protecting and promoting the right to health as a human right. All these factors give rise to the HRBAP which is advocated by WHO as a fundamental strategy to develop human well-beings. The primary idea of this approach is to apply the norms and principles of human rights to the design, implementation, monitoring, and evaluation of certain health policies and programs (Note 7).

To enforce this approach on the ground, the concomitant responsibility should under the auspices of the state in terms of threefold: respect, protect, and fulfil. Expounded by the Office of the United Nations High Commissioner for Human Rights and WHO:

- Respect requires States to refrain from interfering directly or indirectly with the right to health.

- Protect requires States to prevent third parties from interfering with the right to health.

- Fulfil requires States to adopt appropriate legislative, administrative, budgetary, judicial, promotional and other measures to fully realize the right to health.

These requirements stress state accountability from a legal perspective. Strongly influenced by the international community, states have to take steps to practice their responsibility in these aspects. Among various measures, the majority is concentrated on acknowledging the right to health as a legally enforceable right. Nevertheless, these efforts raise another controversial question: does the adoption of the human rights discourse impede the enforcement of the right to health? Geuri \& Brinks (2012) affirm that introducing human rights discourse in protecting the right to health $d e$ 
facto complicates the enforcement by pointing out the big difference between enforcing the right to health and enforcing the right to health as a human right. O'Neil (2000, p. 105) attributes these impediments to the lack of well-identified duty-bears. Besides, it needs to point out another two parameters which pose a profound influence on addressing the state accountability to implement the HRBAP.

\subsubsection{The Force of the International Human Rights Documents}

The force of international documents is a controversial issue. Admittedly, these documents are legally binding once ratified. However, "legally binding" is a different concept from "legally enforceable". Whether a ratified document can be legally enforceable or not depends on domestic legal systems. Generally, the procedure for adopting and interpreting these documents relates to domestic constitutional laws. Thus, the key issue is changed into whether these constitutional laws are legally enforceable or not. Few South American countries, such as Brazil and Costa Rica, have special legal procedures to deal with constitutional cases. Yet, their positive impact is limited. In a country without such legal procedures, or even without an independent judicial system like China, protecting and promoting the health at an individual level by implementing the international human rights documents seems even harder.

\subsubsection{The Ambiguity between the Right to Health and the Right to Health Care}

Protecting and promoting health as a human right is a common practice. Health care as a tool to achieve health is widely accepted (Sen, 2001). It is, therefore, reasonable to correlate health care with human rights (Note 8). Just like scholars Gruskin, Mills \& Tarantola (2007, p. 449) once pointed out, "human rights should be imperative in delivery of care and implementation of public health programs." Whereas, treating health as a human right is not equivalent to saying that individuals have a human right to health care. Numerous articles have been published on this issue from different perspectives whereby no consensus has been reached so far (including Beauchamp \& Faden, 1979; Pieterse, 2006; Singh, Govender, \& Mills, 2007; Buijsen, 2010; Juškevičius \& Balsienė, 2010; Eleftheriadis, 2012; Ram-Tiktin, 2012; Gross 2013; Ruger J, Ruger T, \& Annas, 2015). Judging by the debates, there are several parameters obstructing the efforts to entitle individuals to a human right to health care. First of all, it might pose a conflict of interest. Health as a status of well-being can be achieved by different people simultaneously. In other words, there is no conflict of interest in health itself. Conversely, the conflict of interest exists in health care because of the limited resources. This situation is even worse under the influence of advanced technology and irrational individual choices. Therefore, it seems impossible to entitle every individual to a human right to health care. Secondly, there is a risk of violating other kinds of human rights. The issue is more serious in tax-funded healthcare systems. Entitling people to a human right to health care equals to giving them a privilege to claim whatever health care they want. However, satisfying these claims in a tax-funded healthcare system means putting up taxes. An increasing tax permits the coercion of the worse off for making claims on the well off to pay for their medical expenses, which might deprive the right to free choices of the well off. Blackstone (1976, p. 401) aptly revealed the fact by arguing, "The emphasis on need as fundamental for the distribution of goods and services would require some sort of welfare state, and that a welfare state, with its redistribution of wealth and additional restrictions on human action, violates individual freedom and traditional property rights." In addition, casting people as the worse off in health care more or less makes demeaning judgments upon these people. Thirdly, increasing the financial budget for health care indicates decreasing the investment in other fields, like education, which are equally important in consideration of human rights. Last but not least, covering too much impedes the implementation of human rights themselves (Note 9). Too wide a scope will expose human rights to the threat of abuse. The efforts to broaden the spectrum of the human rights concept are exactly a violation of the human rights concept itself (Van Duffel, 2013). The ambiguities and disagreements over the scope and the content of the human rights might weaken the practical value of rights. Thus, the human rights needs to be taken seriously, especially on the part of distinguishing human rights claims from other human desires.

To make a long story short, it is beyond the question that whether emphasizing state accountability is a good or bad strategy to enforce the HRBAP. The aim of this paper is to point out that efforts, which have been taken by national and international community so far, are trapped in a circle of overemphasizing or understating state accountability. Since the international community has a strong tendency of addressing state accountability in implementing the HRBAP to design a just healthcare system, few attention is given to the responsibility of other stakeholders, in particular the responsibility of individuals (Note 10).

\subsection{Reaffirming Individual Responsibility in Constructing Healthcare Systems towards Justice}

The second generation of human right is characterized by emphasizing state accountability. Since the right to health belongs to the second generation of human rights, it is typically for the HRBAP to address state accountability when issues related to the right to health. However, drawbacks arise when implementing the HRBAP by emphasizing state accountability to design a healthcare system. Therefore, it might be a misleading assumption that the HRBAP should centralize state accountability in designing a healthcare system. As a framework with the aim of supporting all kinds of 
human rights, the HRBAP should take consideration of other stakeholders' responsibility, particularly the individual responsibility, in designing a just healthcare system.

\subsubsection{Individual Responsibility Values Solidarity in the HRBAP}

Although solidarity is embedded in the International Bill of Human Rights (Note 11), there is still a disagreement over whether the solidarity should be explicitly recognized as a solitary principle of human rights or not. Karl Vasak (1984, pp. 837-839) suggests that besides the first generation (recognized by the International Covenant on Civil and Political Rights) and the second generation (recognized by the International Covenant on Economic, Social, and Cultural Rights), there should be a third generation of human rights concerning solidarity. Recognizing solidarity rights encourages the cooperative participation of every individual. In principle, cooperative participation not only creates additional benefits but also provides a stable social order for individuals to develop their human well-beings (Wellman, 2000, p. 642). However, whether the third generation of human rights should be legally recognized is still a controversial issue on account of the fact that a new right should be formulated step by step (Alston, 1982). Regardless of the disagreement, the importance of valuing solidarity in human rights is affirmed. After all, solidarity is equally important for the HRBAP since the HRBAP follows the basic principle of human rights. The question ahead is how to value solidarity in the HRBAP. It might confront many criticisms if standing with the state to give priority to the sustainability of the healthcare system by setting limitations to the individual right to health. However, it makes easier to accept if the idea is approached in another way: valuing solidarity in the HRBAP through promoting individual responsibility in health care.

Advocating individual responsibility does not forego the HRBAP to health. In contrast, it is embodied in the basic principles of the HRBAP, which makes the HRBAP even stronger in practice. In theory, the basic principles of the HRBAP are universality and inalienability, indivisibility, inter-dependence and inter-relatedness, equality and non-discrimination, participation and inclusion, accountability and rule of law (Note 12), among which the principle of equality and non-discrimination and the principle of participation and inclusion surely value solidarity by expecting individuals to take responsibility from different dimensions. The principle of equality and non-discrimination requires individuals to improve their self-management skills in health which is a way to look after the health of others. The principle of participation and inclusion needs the transparency of healthcare information which requires individual patients to provide correct and adequate information about his or her health status and acting on the physicians' advices.

\subsubsection{Promoting Individual Responsibility from an Ex Ante Perspective}

Promoting individual responsibility from either an ex ante perspective or an ex post perspective makes a difference. The ex-ante aspect concerns with prevention while the ex-post aspect emphasizes punishment. Advocating individual responsibility from an ex post perspective is likely to use individual responsibility as an excuse to punish someone for their avoidable reckless behaviors. Conversely, advocating individual responsibility from an ex ante perspective will contribute to both individuals and society as a whole. At the individual level, it confirms to the basic principles of human rights, in particular the principle of autonomy. Furthermore, it provides space for individuals to make free choices about his or her lifestyle while warning them that they should be conscious about their choices. It persuades individuals to make rational choices independently by selecting suitable health care which is indirectly beneficial to sustain a healthcare system. At the societal level, advocating individual responsibility in health care from an ex ante perspective is worthwhile to alleviate the financial burden of government. It will be helpful to government in striking a balance among various social goals.

\subsubsection{Individual Responsibility and the Personal Choices of Lifestyles}

Unhealthy lifestyles, such as smoking, eating fatty food, as well as drinking much alcohol are known to increase the risk of various diseases, such as diabetes, obesity and cancers (Cappelen \& Norheim, 2005; 2006; Steinbrook, 2006). Thus, the question arises whether a person suffering from a chronic disease should be denied access to such medical services as organ transplant because of his smoking history. The affirmative answer seems cruel and counterintuitive. Apparently, choosing lifestyle is a personal issue without allowing any external interference. However, this private affair will be automatically converted into a public issue when he or she makes a claim for medical services. Under limited medical resources, every individual exerts competitive influences on one another. This implies that individuals should be conscious of their reckless behavior and take responsibility in managing their health.

Someone might bolster the objection that the preference of lifestyle is not only cultivated by each individual but also determined by his or her economic situation. Studies show that it is much more common for the socio-economically worse off to lead an unhealthy lifestyle which worsens their situation (Anderson, Dalton, Lynch, Johansen \& Holtug, 2013 , p. 4). However, wealth is not the decisive factor of people's choices of lifestyles. Whether individuals voluntarily choose those reckless behaviors in health is the key issue. In response to the issue, Dworkin (2013, p. 299) proposes a mandatory insurance scheme as an assessment. If individuals reject to enroll in the mandatory insurance, then it is safe 
to say that they voluntary choose reckless behavior. John Roemer $(1993$, pp. 150-151; 1998) argues to ascertain whether choices are indeed voluntary by having other individuals, belonging to the same group, testifying whether they would make the same choice. If people from the same the group opt for the same, then the voluntary choices are within expectation while any disadvantage stem from those choices should be compensated.

Overall, raising the issue of individual responsibility in health care has positive and negative aspects. Positively, promoting individual responsibility asserts the feeling of self-control in one's own life and being active in monitoring and improving one's own well-being. Negatively, it consists of the individual's potential feeling of self-blame which is bad for their health, and also the moral criticism, when, unavoidably, the worse off are being abandoned (Guttman \& Ressler, 2001, p. 121).

\section{Conclusion}

The proposed strategy can be approached in the Chinese healthcare system on two levels: individual and governmental. On the individual level, the demand of health care should be controlled within a reasonable magnitude, especially on the part of end-of-life care. In order to achieve it, people need to be educated to face up to pains and deaths, trust physicians, and make rational decisions in health care. For these people who lack legal capacity, such as children and mental patients, their surrogates should make rational choices following the principle of "best interpretation of will and preferences" rather than the "the best interests" (UN CRPD/C/GC/1). Furthermore, making a rational choice in health care is highly influenced by governmental measures. Therefore, attention should be switched to how to provide the conditions, besides the financial budget, which enable individuals to manage their personal health. Firstly, the adequacy and transparency of healthcare information are extremely important. Medical information should be not only provided adequately but also delivered in a readable format. Secondly, paternalism is unavoidable in health care. Health care is a professional area in which physicians play an essential role. Neither the patients nor their surrogates can make rational decisions without physicians' suggestions. However, under the institutional deficiencies of the Chinese healthcare system, the bond of trust between patients and physicians is weakened by physicians' financial incentives. Measures need to be taken to reconstruct the structure of physicians' salaries (e.g. adopt pay-for-performance to improve health care) while regulating and monitoring their medical practices. Thirdly, people need to be educated, especially on the importance of a healthy lifestyle. For instance, certain taxes and advertisements on tobacco and alcohol are issued for discouraging individuals from smoking and excessive drinking. Moreover, exhibiting the connection between fast-food and obesity aims at reminding people to care about their eating habits. Fourthly, people need an effective remedy system to against inappropriate interferences.

Compared to implement the HRBAP through addressing state accountability to design a just healthcare system, promoting individual responsibility in the HRBAP is a more feasible strategy in the Chinese context (Note 13).

\section{Acknowledgements}

The authors offer thanks to China Scholarship Council and Erasmus University Rotterdam for financial support. The authors would like to thank Professor Wei Yi for her valuable suggestions on the earliest draft of this paper.

\section{References}

Alston, P. (1982). A Third Generation of Solidarity Rights: Progressive Development of Obfuscation of International Human Rights Law? Netherlands International Law Review, 29(3), 307-322. https://doi.org/10.1017/S0165070X00012882

Anderson, M. M., Dalton, S. O., Lynch, J., Johansen, C., \& Holtug, N. (2013). Social Inequality in Health, Responsibility and Egalitarian Justice. Journal of Public Health, 35(1), 4-8. https://doi.org/10.1093/pubmed/fdt012

Beauchamp, T. L., \& Faden, R. R. (1979). The Right to Health and the Right to Health Care. The Journal of Medicine and Philosophy, 4(2), 118-131. https://doi.org/10.1093/jmp/4.2.118

Blackstone, W. T. (1976). On Health Care as a Legal Right: an Exploration of Legal and Moral Foundation. Georgia Law Review, 10,391-418.

Buijsen, M. (2010). Autonomy, Human Dignity, and the Right to Healthcare: A Dutch Perspective. Cambridge Quarterly of Healthcare Ethics, 19(3), 321-328. https://doi.org/10.1017/S0963180110000095

Cappelen, A. W., \& Norheim, O. F. (2005). Responsibility in Health Care: A Liberal Egalitarian Approach. Journal of Medical Ethics, 31(8), 476-480. https://doi.org/10.1136/jme.2004.010421

Cappelen, A. W., \& Norheim, O. F. (2006). Responsibility, Fairness and Rationing in Healthcare. Health Policy, 76(3), 312-319. https://doi.org/10.1016/j.healthpol.2005.06.013

Chapman, A. R. (1994). Health care reform: a human rights approach. Washington, D. C.: Georgetown University Press. 
Chapman, A. R. (2010). The Social Determinants of Health, Health Equity, and Human Rights. Health and Human Rights, 12(2), 17-30.

Chapman, A. R., Forman, L., \& Lamprea, E. (2015). Evaluating Essential Health Packages from A Human Rights Perspective. Journal of Human Rights. https://doi.org/10.1080/14754835.2015.1107828

Daniel, N. (2001). Justice, Health, and Healthcare. The American Journal of Bioethics, 1(2), 2-16. https://doi.org/10.1162/152651601300168834

Daniel, N. (2008). Just Health: Meeting Health Needs Fairly. NY, USA: Cambridge University Press.

Daniel, N. (2011). Individual and Social Responsibility for Health, In Responsibility and Distributive Justice, ed. Carl Knight, and Zofia Stemplowska, Oxford: Oxford University Press. https://doi.org/10.1093/acprof:oso/9780199565801.003.0014

Daniel, N., \& Sabin, J. (1998). The Ethics of Accountability in Managed Care Reform. Health Affairs, 17(5), 50-64. https://doi.org/10.1377/hlthaff.17.5.50

Daniel, N., \& Sabin, J. (2002). Setting Limits Fairly: Can We Learn to Share Medical Resources? NY, USA: Oxford University Press. https://doi.org/10.1093/acprof:oso/9780195149364.001.0001

Daniel, N., \& Sabin, J. (2008). Accountability for Reasonableness: An Update. BMJ. https://doi.org/10.1136/bmj.a1850

Dworkin, R. (2013). Taking Rights Seriously. LONDON, UK and NY, USA: Bloomsbury Academic.

Eleftheriadis, P. (2012). A Right to Health Care. Journal of Law, Medicine and Ethics, 40(2), 268-285. https://doi.org/10.1111/j.1748-720X.2012.00663.x

Fang, P. (2015). Green Book of Health Reform and Development. Beijing: Renmin Press.

Fisher, K. R., Shang, X., \& Blaxland M. (2010). Review Article: Human Rights Based Social Policies---Challenges for China. Social Policy and Society, 10(1), 71-77. https://doi.org/10.1017/S1474746410000400

Geuri, V., \& Brinks, D. M. (2012). Human Rights as Demands for Communicative Action. The Journal of Political Philosophy, 20(4), 407-431. https://doi.org/10.1111/j.1467-9760.2012.00421.x

Gross, A. (2013). Is There a Human Right to Private Health Care? Journal of Law, Medicine and Ethics, 41(1), 138-146. https://doi.org/10.1111/jlme.12010

Gruskin, S., Mills, E. J., \& Tarantola D. (2007). History, Principle, and Practice of Health and Human Rights. The Lancet, 370(9585), 449-455. https://doi.org/10.1016/S0140-6736(07)61200-8

Guttman, N., \& Ressler, W. H. (2001). On Being Responsible: Ethical Issues in Appeals to Personal Responsibility in Health Campaigns. Journal of Health Communication, 6(2), 117-136. https://doi.org/10.1080/108107301750254466

Ho, C. S. (2014). Health Rights at the Juncture between State and Market: The People's Republic of China, In The Right to Health at the Public/Private Divide: A Global Comparative Study, ed. Colleen M. Flood and Aeyal Gross, NY, USA: Cambridge University Press. https://doi.org/10.1017/CBO9781139814768.014

Juškevičius, J., \& Balsienè, J. (2010). Human Rights in Healthcare: Some Remarks on the Limits of the Right to Healthcare. Jurisprudence, 4(122), 95-110.

Li, L., Chen, Q., \& Powers, D. (2012). Chinese Healthcare Reform: A Shift toward Social Development. Modern China, 38(6), 630-645. https://doi.org/10.1177/0097700412457913

Liu, Y. (2004). China's Public Healthcare System: Facing the Challenges. Bulletin of the World Health Organization 2004,82(7), 532-538.

Meng, Q., \& Tang, S. (2010). Universal Coverage of Health Care in China: Challenges and Opportunities. World Health Report (2010), Background Paper, 7.

O’Neil, O. (2000). Bounds of Justice. Cambridge: Cambridge University Press. https://doi.org/10.1017/CBO9780511605734

Pieterse, M. (2006). Resuscitating Socio-economic Rights: Constitutional Entitlements to Health Care Services. South African Journal on Human Rights, 22, 473-502.

Ram-Tiktin, E. (2012). The Right to Health Care as a Right to Basic Functional Capabilities. Ethical Theory and Moral Practice, 15(3), 337-351. https://doi.org/10.1007/s10677-011-9322-7

Roberts, M., Hsiao, W., Berman, P., \& Reich, M. (2008). Getting Health Reform Right: A Guide to Improving 
Performance and Equity. NY, USA: Oxford University Press. https://doi.org/10.1093/acprof:oso/9780195371505.001.0001

Roemer, J. E. (1993). A Pragmatic Theory of Responsibility for the Egalitarian Planner. Philosophy \& Public Affairs, 22(2), 146-166.

Roemer, J. E. (1998). Theories of Distributive Justice. Harvard University Press.

Ruger, J. P., Ruger, T. W., \& Annas, G. J. (2015). The Elusive Right to Health Care under U.S. Law. The New England Journal of Medicine, 372(26), 2558-2563. https://doi.org/10.1056/NEJMhle1412262

Schrecker, T., Chapman, A. R., Labonté, R., \& De Vogli, R. (2010). Advancing Health Equity in the Global Marketplace: How Human Rights Can Help. Social Science \& Medicine, 71(8), 1520-1526. https://doi.org/10.1016/j.socscimed.2010.06.042

Sen, A. (2001). Foreword, In Is Inequality Bad for Our Health? ed. Norman Daniels, Beacon Press.

Singh, J. A., Govender, M., \& Mills, E. J. (2007). Do Human Rights Matter to Health? The Lancet, 370(9586), 521-527. https://doi.org/10.1016/S0140-6736(07)61236-7

Steinbrook, R. (2006). Imposing Personal responsibility for health. The New England Journal of Medicine, 355, 753-756. https://doi.org/10.1056/NEJMp068141

Toebes, B. (1999a). The Right to Health as A Human Right in International Law. Antwerpen: INTERSENTIA/HART.

Toebes, B. (1999b). Towards an Improved Understanding of the International Human Rights to Health. Human Rights Quarterly, 21, 661-679. https://doi.org/10.1353/hrq.1999.0044

Toebes, B. (2006). The Right to Health and the Privatization of Health Care Services: A Case Study of the Netherlands. Health and Human Rights, 9(1), 102-127. https://doi.org/10.2307/4065392

Toebes, B. (2015). Human Rights and Public Health: Towards A Balanced Relationship. International Journal of Human Rights, 19(4), 188-504. https://doi.org/10.1080/13642987.2015.1044814

Van Duffel, S. (2013). Moral Philosophy, In The Oxford Handbook of International Human Rights Law, ed. Dinah Shelton, Oxford: Oxford University Press. https://doi.org/10.1093/law/9780199640133.003.0003

Vasak, K. (1984). Pour une troisième génération des droits de l'homme, In Studies and Essays on International Humanitarian Law and Red Cross, ed. Swinarski, Springer.

Wang, S. (2004). China's Health System: From Crisis to Opportunity. Yale-China Health Journal, 3, 5-49.

Wellman, C. (2000). Solidarity, the Individual and Human Rights. Human Rights Quarterly, 22(3), 639-657. https://doi.org/10.1353/hrq.2000.0040

World Health Organization. (2008). The World Health Report 2008-Primary Health Care (Now More Than Ever). Available at: http://www.who.int/whr/2008/en/

World Health Organization, World Bank Group, China's Ministry of Finance, National Health and Family Planning Commission, and Ministry of Human Resources and Social Security. (2016). Healthy China: Deepening Health Reform in China. Available at: http://www.wpro.who.int/china/publications/2016-health-reform-in-china/en/

Yip, W., \& Hsiao, W. (2015). What Drove the Cycles of Chinese Health System Reforms? Health Systems \& Reform, 1(1), 52-61. https://doi.org/10.4161/23288604.2014.995005 


\section{Notes}

Note 1. This scope is defined by the Information Office of the State Council, Medical and Health Services in China, The People's Republic of China, December 2012, Beijing.

Note 2. For instance, The Mental Health Law of the People's Republic of China (2012); Law of the People's Republic of China on the Prevention and Control of Occupational Diseases (2011); Law of the People's Republic of China on Maternal and Infant Health Care (2009); "Yiliao Shigu Chuli Tiaoli” which refers to Regulations on Handing Medical Accidents.

Note 3. According to Yip and Hsiao (2015, pp. 54-55), infant mortality is decreased "from 200 to 57 per 1000 while the life expectancy is extended from 45 to 68 years." The data involved (10 Aug., 2015), available at http://esa.un.org/wpp/.

Note 4. Those international documents are issued from diverse perspectives. The following list of documents with signifying/ratifying time in brackets is only concerning the field of healthcare. International Convention on the Elimination of All Forms of Racial Discrimination (only ratifying in 1981); International Covenant on Civil and Political Rights (only signifying in 1998); International Covenant on Economic, Social and Cultural Rights (1997/2001); Convention on the Elimination of All Forms of Discrimination against Women (1980/1980); Convention on the Rights of the Child (1990/1992); Convention on the Rights of Persons with Disabilities (2007/2008).

Note 5. "Give priority to efficiency with due consideration to fairness" was put forwarded as a solitary principle in the "Decision for Establishment of Socialist Market Economic System" which was affirmed by the $15^{\text {th }}$ National Congress of the Communist Party of China.

Note 6. According to the National Bureau of Statistics of China, patient's paid 20 percent of total health expenditure out-of-pocket in 1978 while shouldered 60 percent in 2001.

Note 7. The detailed explanation of the Human Rights-Based Approach from WHO (20 Aug., 2016), available at http://www.unicef.org/policyanalysis/rights/index_62012.html; http://www.who.int/trade/glossary/story054/en/_

Note 8 . Interpreted by the General Comment No. 14, the right to health should at least be extended to "timely and appropriate healthcare." UN Committee on Economic, Social, and Cultural Rights (CESCR).

Note 9. Several international documents, such as The Declaration toward a Global Ethic, Universal Declaration on Human Responsibilities, Declaration of Human Duties and Responsibilities as well as basic documents produced by International Council on Human Rights have been promulgated with focus on rising individual responsibility during these days. Unfortunately, those provisions undergo lots of criticisms and correspond poorly with realities on national levels.

Note 10. The Stanford Encyclopedia of Philosophy, Human Rights (20 Aug., 2016), available at http://plato.stanford.edu/entries/rights-human/.

Note 11. According to the International Bill of Human Rights, limitations on the human rights are allowed when they are determined and prescribed by law and are necessary for certain considerations. The specific rules are: Article 29 (2) of the Universal Declaration of Human Rights; Article 4 and Article 8 (1) of the International Covenant on Economic, Cultural and Social Rights; Article 18 (3) of the International Covenant on Civil and Political Rights.

Note 12. HRBA Portal, The Human Rights Based Approach to Development Cooperation: Towards a Common Understanding Among UN Agencies (20 Aug., 2016), available at

http://hrbaportal.org/the-human-rights-based-approach-to-development-cooperation-towards-a-common-understandingamong-un-agencies.

Note 13. Recently, the Chinese government has set out a new health policy that aims at increasing the individual payment ratio of health insurance to some extent. "Opinions of the State Council on Adjusting the Basic Medical Insurance Schemes" No. 3 [2016] of the State Council.

\section{Copyrights}

Copyright for this article is retained by the author(s), with first publication rights granted to the journal.

This is an open-access article distributed under the terms and conditions of the Creative Commons Attribution license which permits unrestricted use, distribution, and reproduction in any medium, provided the original work is properly cited. 